\title{
A modification of the Hulse lickerandum: Preliminary studies and suggested applications
}

DON R. JUSTESEN, VA HOSPITAL, KANSAS CITY, MISSOURI AND KANSAS UNIVERSITY MEDICAL CENTER
DANIEL M. LEVINSON 2 AND MARVIN DALEY 3 , UNIVERSITY OF MISSOURI AT KANSAS CITY

Three problems bearing on the utility of the rat's tongue lick were attacked with provisional success: first, slight modification of an extant operandum-feeder afforded a simple and flexible means of measuring and reinforcing the licking operant; second, Ss' performances on FR schedules demonstrated that the tongue-lick, while possessing respondent properties, is unequivocally a "free" operant; and third, gross examination of 10 rats' tongues following 55,000 to 127,000 licking responses revealed no observable deleterious changes. Several applications are suggested.

Work reported or cited by Hulse (1966) and Stricker (1966) has established that the rat's tonguelick is rapidly conditioned and quite sensitive-both to quality and schedule of reinforcement. Hulse has also drawn attention to respondent properties of the tongue-lick and several Es (see, e.g., DeBold, Miller, \& Jensen, 1965) have indeed found it amenable to classical conditioning. That rats have exhibited stable licking to low-ratio intermittent schedules (Hulse, Snyder, \& Bacon, 1960) would be expected-a single water reinforcement may elicit a burst of eight or more licks. Demonstration of the tongue-lick as a useful "free" operant would therefore entail stable performance on an intermittent schedule the ratio of which exceeds the number of responses in a respondent burst.

Licking to FI and VI schedules has been reported (see Stricker, 1966) but these schedules do not necessitate high consecutive numbers of unreinforced responses. So far as we know, experiments with appropriate schedules, e.g., a fairly high fixed-ratio arrangement, have not been reported.

Our aim in these preliminary studies was not only to examine rats' fixed-ratio performances but to shed light on two problems that also bear on the tonguelick's experimental utility. We sought, first, to secure an operandum that would be simple, flexible, and reproducible in the combined sense of ease-of-construction and uniformity of inter-unitoperation. Second, it seemed imperative to examine tongues of animals subjected to fairly prolonged scheduling.

The lickerandum. Many Es have employed ordinary stainless-steel drinking tubes to record licking rates; and a few, to provide intermittent reinforcement of licking. We tried, then abandoned stainless tubes because Ss were frequently observed to "double-trip" the electronic sensor; i.e., S's tongue would first contact the lower- and then recontact the upper-margin of a drinking tube's orifice during a single licking movement. Too, residual fluid accessible to S's tongue was often left in a drinking tube following a programmed reinforcement.

We subsequently adopted a combined operandumfeeder which was developed in conjunction with an electromechanical pump by Hulse (1960). The pump's relative complexity and high cost, however, led us to substitute a gravity-fed, electric valve (see Fig. 1 for photographic detail). Specifications for constructing the operandum-feeder (we dubbed it the "lickerandum") are given in Hulse's 1960 report. Briefly described, it is a Plexiglas cylinder with a $2 \mathrm{~mm}$ diameter fluid channel that terminates just above an equally small, flush brass contact. As we employed it, when S's tongue touched the brass contact, a low current sensing circuit was activated which momentarily opened a fluid valve. Fluid was ejected from the lickerandum in droplet form and, with the controlling circuits used in our experiments, was posited in S's mouth with a latency below $75 \mathrm{msec}$. A Lehigh Valley Electronics Model 1520 contact relay was used as the licking sensor. A Grason-Stadler E1100H electronic timer set to the "50 msec." function served to gate the solenoid of an ASCO Model 82624 fluid-valve. The head of pressure in the reservoir was gravitationally adjusted to deliver .05 $\mathrm{ml}$ reinforcements of $10 \%$ sucrose solution.

Scheduling. Ten mature Holtzman males underwent 25 to 43 sessions in a 10 in. long $\times 8$ in. wide $x 7$ in. high conditioning chamber and were maintained through-

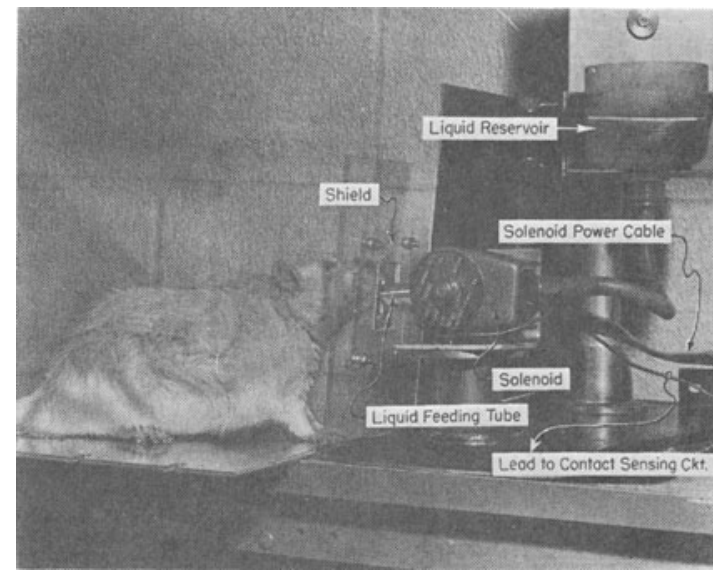

Fig. 1. The lickerandum and associated apparatus was removed from a conditioning chamber to permit unobstructed photographic viewing. Normally, the Plexiglas shield forms one wall of a conditioning chamber. 


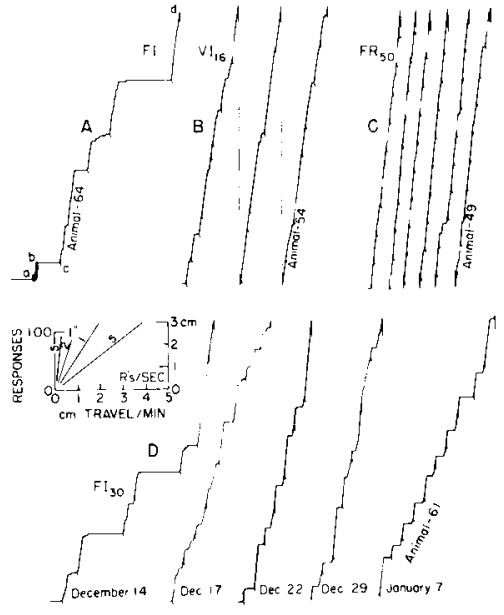

Fig. 2. Cumulative records that reflect tongue-licking to different schedules of reinforcement. In Fig. 2-A, an initially experimentally naive $S$ was given 30 consecutively reinforced licks (a to b), followed by a $60 \mathrm{sec}$. time-out (b to $c$ ); from $c$ to $d$, $S$ responded to a FI-60 sec. schedule. Figure 2-B shows the record of the first 1500 licking responses of another $S$ on a VI-16 sec. schedule; $S$ had received only one prior session of conditioning. In Fig. 2-C, the entire record from another $S$ 's 27 th conditioning session on a FR-50 schedule is shown. In Fig. 2-D, samples of performance across several weeks of FI-30 sec. scheduling are shown for the fourth $S$; the records reflect the first 500 tonguelicking responses from five different sessions.

out on 21-23 hro of food and water deprivation. In the first session, the experimentally naive Ss were "primed" by placing a drop of the sucrose solution on the brass contact of the lickerandim, then permitted to lick for 30 continuous reinforcements. Following a $60 \mathrm{sec}$. time-out (no illumination in the conditioning chamber), each $\mathrm{S}$ was shifted to one of four intermittent schedules for 30 additional reinforcements. During each subsequent session, each S's particular intermittent schedule was in effect until 60 reinforcements had been received; at this juncture, automatic circuitry extinguished chamber illumination and signaled $\mathrm{E}$ to remove $\mathrm{S}$, A sampling of cumulative records is shown in Fig. 2 .

Two Ss each made successful shifts from CRF to: FI-30 sec., FI-60 sec.s or VI-60 sec. schedules during the first session. Some fairly lengthy lapses in responding occurred-and persisted through one to three subsequent sessions-but all Ss returned to work at the lickerandum until reaching the intrasession criterion of 60 reinforcements. Cumulative curves on these Ss continued, however, to change across scheduling sessions (Fig. 2-D), but did not eventuate (in the case of the two FI Ss) in the negative scallop characteristic of key-pecking pigeons and lever-pressing rats. This observed persistence of responding immediately after reinforcement may be due to the respondent properties of the tongue-lick, or to the absence of consummatory time-outs.

None of the four remaining Ss made a successful direct transition from CRF to a FR-50 schedule. During the first session, Ss extinguished and failed to resume responding within the $20 \mathrm{~min}$. limit established by $\mathrm{E}$ as the criterion for intervention. However, by restarting $S s$ at a lower ratio $(F R-10)$, then increasing ratios across several daily sessions, all Ss were brought to stable responding in less than 10 days. Once stable FR-50 responding occurred, neither rate nor form of cumulative curves exhibited further significant change. Aside from absence of consummatory time-out, the cumulative curves generated by the four rats appear much like those generated by pigeons on comparable FR schedules.

Examination of Ss' Tongues. At completion of the scheduling sessions, the $10 \mathrm{Ss}$ had made from 55,000 to 127,000 licking responses within a two to three month interval. The tongues of all Ss were then visually compared with those of unused cage-mates of the same weights and ages. There was no grossly observable enlarging, no signs of tissue wear or irritation.

Applications. Our findings and those of other Es lead us to the guarded belief that the rat's tongue-lick is a viable operant with some salient applications. With appropriate timing and counting ciruitry, e.g., the lickerandum's fluid valve could provide fixed or rapidly switched delays or quanta of liquid reinforcements. Also, the technique may lend itself to multiple simultaneous measures-by using two, three, or even more lickeranda, titrations of or preferences among solution concentrations, quanta, etc., might more rapidly be measured. Similarly, E could program conventional positive- with conventional negative-reinforcers at very short latencies-or combine these with schedules of intracranial reinforcement.

\section{References}

DeBold, R. C., Miller, N. E., \& Jensen, D. D. Effect of strength of drive determined by a new technique for appetitive classical conditioning of rats. J. comp. physiol. Psychol., 1965, 59, 102108 .

Hulse, S. H., Jr. A precision liquid feeding system controlled by licking behavior. J. exp. Anal. Behav., 1960, 3, 1-3.

Hulse, S. H. Stimulus intensity and magnitude of the licking reflex in rats. Psychon. Sci., 1966, 6, 359-364.

Hulse, S. H., Snyder, H. L., \& Bacon, W. E. Instrumental licking behavior as a function of schedule, volume, and concentration of a saccharine reinforcer. J. exp. Psychol., 1960, 6, 359-364.

Stricker, E. M. The rat's preference for saline solutions as measured by licking reinforced on a variable interval schedule. Psychon. Sci., 1966, 5, 205-206.

\section{Notes}

1. This study was supported by 8200 Funds of the U. S. Veterans Administration.

2. Now at the University of Southern California.

3. Now at the Utah State University. 